\title{
ALAT DETEKSI KANDUNGAN GAS CO DAN NO2 VIA SMS
}

\author{
Yudhi $^{1}$, Aan Febriansyah ${ }^{2}$ \\ Politeknik Manufaktur Negeri Bangka Belitung \\ Kawasan Industri AirKantung Sungailiat Bangka Belitung \\ Yudhijais@gmail.com
}

\begin{abstract}
Increasing the amount of air pollution that causes global warming and the lack of attention to harmful gases such as $\mathrm{CO}$ and NO2 can have negative effects on health can even cause death if it is ignored by those who breathe it. And one of the most popular communications media today is mobile. Therefore, it is necessary to create a tool that can monitor air quality levels and by utilizing advances in technology monitoring system can be seen from a far via SMS. In this paper, we use the type ATmega AVR microcontroller unit 16 as a control center and a GSM modem as a network system that handles communication between the microcontroller to the network using the SMS application. In addition, the system uses the $C$ language as the configuration between the microcontroller and mobile network systems. Air pollution levels were measured with gas sensor MQ-7 that serves to measure levels of CO and MQ-5 to measure NO2 levels. The test results of sensor calibration and sensor MQ-5 MQ-7 which issued the $A D C$ output is changed by using the formula provisions ppm ADC becomes a value in accordance with the standards set by ISPU (Air Pollution Standards Index).
\end{abstract}

Keyword: SMS Application, Modem GSM, ATmega16, Sensor MQ-5, Sensor MQ-7, Standard ISPU

\begin{abstract}
Abstrak
Peningkatan jumlah polusi udara yang menyebabkan pemanasan global dan kurangnya perhatian terhadap gas-gas berbahaya seperti CO dan NO2 dapat memberikan dampak yang negatef bagi kesehatan bahkan dapat menyebabkan kematian jika itu diabaikan oleh orang-orang yang menghirupnya. Dan salah satu media komunikasi yang popular saat ini adalah handphone. Oleh karena itu, perlu dirancang sebuah alat yang dapat memantau tingkat kualitas udara yang dengan memanfaatkan kemajuan teknologi sistem monitoring ini dapat diketahui dari jauh melalui SMS. Dalam alat ini, digunakan mikrokontroler AVR tipe ATmega 16 sebagai unit pusat control dan sebuah modem GSM sebagai sistem jaringan yang menghubungkan komunikasi antara mikrokontroler dengan jaringan menggunakan aplikasi SMS. Selain itu, sistem ini menggunakan bahasa $C$ sebagai konfigurasi antara mikrokontroler dan sistem jaringan handphone. Tingkat polus iudara diukur dengan sensor gas MQ-7 yang berfungsi untuk mengukur kadar CO dan MQ-5 untuk mengukur kadar NO2. Pengujian hasil dilakukan dengan cara pengukuran sensor MQ-5 dan sensor MQ-7 yang mengeluarkan output ADC lalu diubah dengan menggunakan rumus ketentuan ADC menjadi nilai satuan ppm sesuai dengan standar yang ditetapkan oleh ISPU (Indeks Standar Pencemaran Udara).
\end{abstract}

Kata Kunci: Aplikasi SMS, Modem GSM, Atmega16, Sensor MQ-5, Sensor MQ-7, Standar ISPU

\section{PENDAHULUAN}

Pencemaran udara adalah suatu kondisi dimana kualitas udara menjadi rusak dan terkontaminasi oleh zat-zat, baik yang tidak berbahaya maupun yang membahayakan kesehatan tubuh manusia. Pencemaran udara biasanya terjadi di kota-kota besar dan juga daerah padat industri yang menghasilkan gas-gas yang mengandung zat di atas batas kewajaran. Makin sempitnya lahan hijau atau pepohonan di suatu daerah juga dapat memperburuk kualitas udara di tempat tersebut. Semakin banyak kendaraan bermotor dan alat-alat industri yang mengeluarkan gas yang mencemarkan lingkungan akan semakin parah pula pencemaran udara yang terjadi di kawasan tersebut. Untuk itu diperlukan peran serta pemerintah, pengusaha, dan masyarakat untuk dapat menyelesaikan permasalahan pencemaran udara yang terjadi. Adapun gas-gas pencemar udara utama adalah gas CO dan NO2, gas $\mathrm{CO}$ atau karbon monoksida adalah gas yang bersifat membunuh makhluk hidup termasuk 
manusia. Gas CO ini mengganggu pengikatan oksigen pada darah karena CO lebih mudah terikat oleh darah dibandingkan dengan oksigen dan gas-gas lainnya. Pada kasus daerah yang tercemar karbon monoksida dalam kadar $70 \%$ hingga $80 \%$ dapat menyebabkan kematian pada orang. Kemudian gas NO2 dihasilkan oleh asap bahan bakar minyak yang mengandung berbahan sulfur, pembakaran limbah pertanahan, dan proses dalam industri. Dapat menimbulkan gangguan pada saluran pernapasan dari mulai yang ringan hingga yang berat. Gas CO dan NO2 ini tidak berbau dan tidak dapat dilihat, oleh karena itu manusia dan makhluk hidup lainnya tidak dapat mengetahuinya jika gas-gas tersebut ada di sekitarnya. Manusia bisa tahu jika sudah merasakan dampaknya. Untuk menghindari hal itu maka dibuat tugas akhir untuk mendeteksi dan memantau keberadaan gas CO dan NO2 di dalam udara dan akan disimpan setiap detik perubahan data yang dideteksi oleh sensor-sensor pada alat deteksi kandungan gas CO dan NO2 via sms, sehingga diperoleh data keberadaan gas yang terdeteksi setiap detik untuk dapat diolah dan ditampilkan sebagai informasi[1].

\section{METODE PENELITIAN}

\subsection{Flow Chart Pembuatan Alat}

Pelaksanaan pembuatan proyek akhir kami tergambarkan pada flowchart Gambar 2.1.

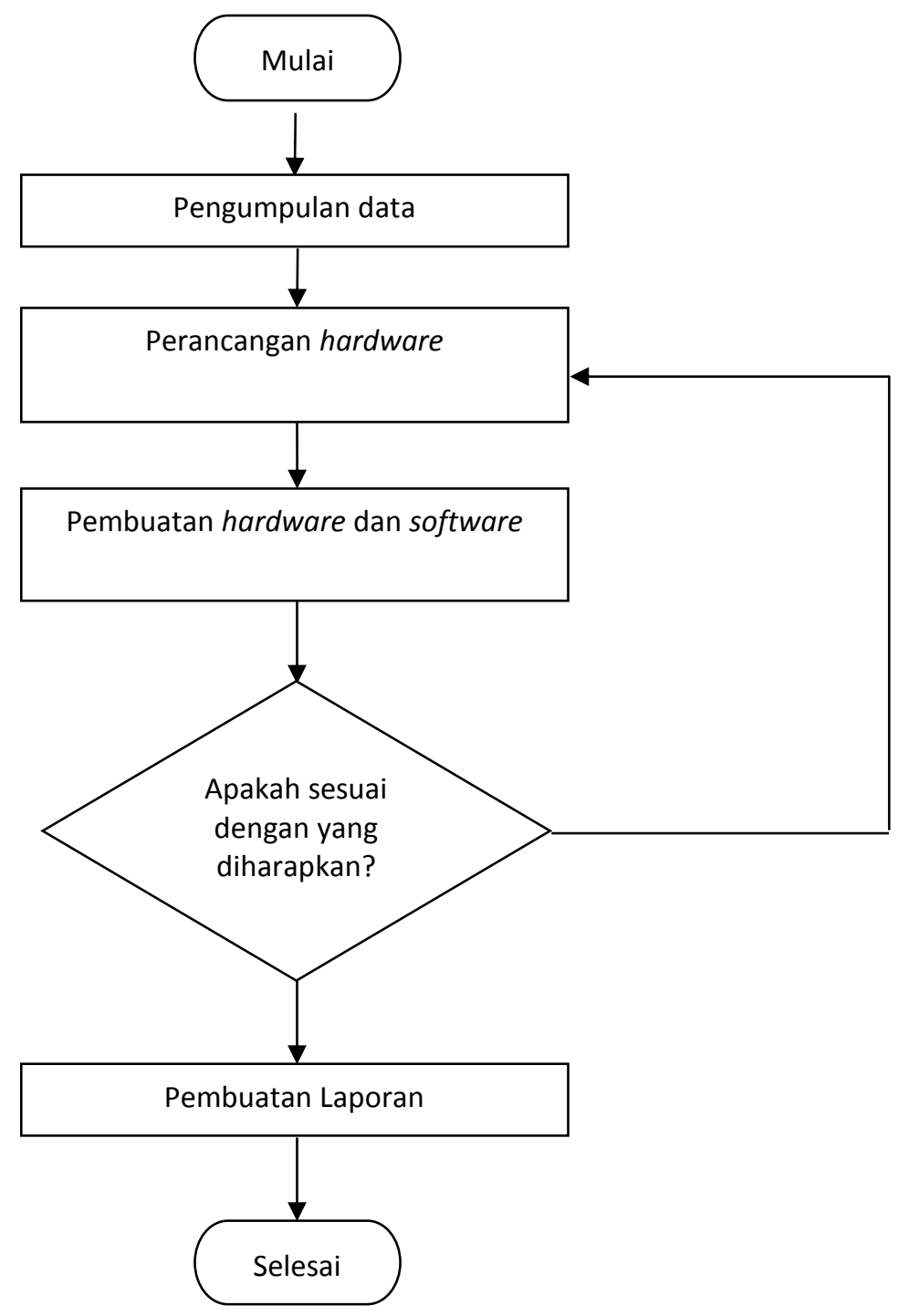

Gambar 2.1 Flow Chart Metode Pelaksanaan 
Dari gambar di atas dapat dijelaskan metode penilitian proyek akhir ini meliputi beberapa data:

\subsection{Pengumpulan Data}

Pengumpulan data berfungsi untuk mendapatkan daftar peralatan dan komponen apa saja yang digunakan dalam pembuatan proyek akhir ini. Selain itu juga untuk mengetahui prinsip kerja penggunaan $L C D$ dan penggunaan modul GSM wavecom. Pada studi ini didapatkan data dari internet, referensi dari buku-buku yang menunjang materi tugas akhir serta bimbingan dosen dan instruktur Polman Negeri Bangka Belitung. Berikut ini adalah metode pengumpulan data secara primer dan sekunder tersebut yaitu:

1. Pengumpulan data secara primer adalah pengumpulan data yang sumber datanya diperoleh secara langsung dari narasumber. Contoh pengumpulan data primer yang dilakukan adalah bimbingan. Bimbingan dari dosen pembimbing sangat dibutuhkan karena tugas dari dosen pembimbing adalah mengarahkan, membantu serta memberi materi. Pengumpulan data dari bimbingan berupa prosedur penggunaan, pembuatan program, dan pembuatan tampilan aplikasi serta perancangan dan pembuatan program.

2. Pengumpulan data secara sekunder adalah pengumpulan data yang sumber datanya diperoleh secara tidak langsung dari narasumber. Contoh pengumpulan data secara sekunder yaitu studi literatur. Studi literatur sangat diperlukan untuk menunjang pembuatan program alat ini, data dari berbagai sumber yang terkait dengan program ini didapat melalui internet dan diambil dari berbagai macam buku yang berhubungan dengan dasar teori materi yang dibuat yaitu pengambilan data tentang tata cara penggunaan modul GSM wavecom.

\subsection{Perancangan Hardware}

Perancangan hardware bertujuan agar alat ini dapat mencapai target yang diinginkan dan semua sistem alat dapat bekerja dengan baik. Setelah perancangan hardware selesai, maka langkah selanjutnya adalah perancangan software alat. Pada tahap perancangan software ini bertujuan untuk mempermudah sistem kontrol alat.

\subsection{Pembuatan Hardware dan Software alat}

Setelah rancangan sistem kontrol alat dirancang maka rancangan tersebut dibuat sesuai dengan rancangan yang telah dirancang sebelumnya. Pada tahapan ini ada beberapa hal yang dilakukan yaitu:

a) Merakit konstruksi alat.

b) Pembuatan rangkaian dan pemasangan Liquid Crystal Display (LCD).

c) Pemasangan keypad4x4.

d) Membuat rangkaian dan pemasangan sistem minimum ATMega16.

e) Membuat rangkaian dan pemasangan modul sensor MQ-7 danMQ-5.

f) Pemasangan modul GSM wavecom.

Setelah hardware dibuat maka langkah selanjutnya adalah pembuatan software. Pada langkah ini pembuatan software dilakukan dengan menggunakan software CodevisionAVR.

\subsection{Uji Coba}

Proses uji coba dilakukan sebagai tolak ukur berhasil atau tidaknya alat deteksi kandungan gas CO dan NO2 dengan Mikrokontroler dan Modem GSM yang dibuat. Dengan begitu, kita dapat mengevaluasi sistem kerja dari alat. Apabila sistem kerja alat tidak sesuai dengan yang diinginkan, maka kembali ke proses perancangan hardware dan software untuk perbaikan sistem kerja pada alat.

Di bawah ini beberapa percobaan yang dilakukan pada pembuatan alat ini :

a) Komunikasi antara Handphone ke alat menggunakan modul GSM wavecom.

b) Komunikasi antara Mikrokontroler kealat.

c) Komunikasi keypad 4x4 dan LCD ke Mikrokontroler.

\section{HASIL PENELITIAN DAN PEMBAHASAN}

\subsection{Pengujian Sistem Minimum ATMega16}

Pengujian rangkaian mikrokontroler ATMega16 dilakukan dengan memberikan program sederhana. Program sederhana dibuat untuk melakukan pengukuran tegangan tiap-tiap pin dengan cara memberi logic 0 (low) dan logic 1 (high). Untuk mengetahui apakah rangkaian mikrokontroler tersebut 
bekerja, maka digunakan LED sebagai indikator. Berikut ini adalah blok diagram untuk pengukuran Active High dan Active Low tiap-tiap pin pada port mikrokontroler ATMega16.

Tabel 3.1 Hasil Pengukuran Active High Mikrokontroler

\begin{tabular}{cccccc}
\hline & \multicolumn{5}{c}{ PORT ATMega16 } \\
\cline { 2 - 6 } PIN & $\mathrm{A}$ & $\mathrm{B}$ & $\mathrm{C}$ & $\mathrm{D}$ & \\
\cline { 2 - 6 } & High & High & High & High & Kondisi led \\
\hline 0 & $4,86 \mathrm{~V}$ & $4,8 \mathrm{~V}$ & $4,85 \mathrm{~V}$ & $4,85 \mathrm{~V}$ & Nyala \\
1 & $4,86 \mathrm{~V}$ & $4,8 \mathrm{~V}$ & $4,85 \mathrm{~V}$ & $4,78 \mathrm{~V}$ & Nyala \\
2 & $4,86 \mathrm{~V}$ & $4,8 \mathrm{~V}$ & $4,85 \mathrm{~V}$ & $4,85 \mathrm{~V}$ & Nyala \\
3 & $4,86 \mathrm{~V}$ & $4,8 \mathrm{~V}$ & $4,85 \mathrm{~V}$ & $4,85 \mathrm{~V}$ & Nyala \\
4 & $4,86 \mathrm{~V}$ & $4,8 \mathrm{~V}$ & $4,85 \mathrm{~V}$ & $4,85 \mathrm{~V}$ & Nyala \\
5 & $4,86 \mathrm{~V}$ & $4,8 \mathrm{~V}$ & $4,85 \mathrm{~V}$ & $4,85 \mathrm{~V}$ & Nyala \\
6 & $4,86 \mathrm{~V}$ & $4,8 \mathrm{~V}$ & $4,85 \mathrm{~V}$ & $4,85 \mathrm{~V}$ & Nyala \\
7 & $4,86 \mathrm{~V}$ & $4,8 \mathrm{~V}$ & $4,85 \mathrm{~V}$ & $4,85 \mathrm{~V}$ & Nyala \\
\hline
\end{tabular}

*Sumber: Hasil pengukuran

Pengujian selanjutnya sama seperti sebelumnya, yakni untuk mengetahui tegangan keluar mikrokontroler. Namun pengujian ini dilakukan dengan cara mengubah output value setiap port menjadi 0 (low). Setelah program di unduh, kemudian dilakukan pengukuran dengan multitester digital. Output masing-masing port dihubungkan dengan kaki positif pada avometer dan kaki negatif pada multitester dihubungkan pada ground. Berikut adalah program sederhana untuk pengukuran Active Low pada mikrokontroler ATMega16.

Dari pengujian yang telah dilakukan maka nilai ADC yang didapatkan oleh sensor MQ-7 yaitu nilai minimum ADC sensor adalah 300 dan nilai maksimum ADC sensor adalah 496 dari ketiga sumber asap yang telah duji dan tiga jarak yang telah diukur. Tabel 3.2 menunjukkan hasil pengujian sensor MQ-7 dengan tiga sumber.

Tabel 3.2 Nilai $A D C$ hasil pengujian sensor MQ-7

\begin{tabular}{cccc}
\hline & & \multicolumn{2}{c}{ Sensor MQ-7 } \\
\cline { 3 - 3 } Jarak & Sumber & Nilai ADC & $\begin{array}{c}\text { Nilai ADC } \\
\text { Maksimum }\end{array}$ \\
\cline { 3 - 4 } Jarak 1,5 Meter & Asap rokok & 300 & 302 \\
& Asap motor & 323 & 329 \\
Jarak 1 Meter & Asap Obat nyamuk & 300 & 302 \\
& Asap rokok & 300 & 302 \\
Sumber asap mengenai & Asap motor & 327 & 340 \\
sensor & Asap Obat nyamuk & 300 & 302 \\
& Asap rokok & 382 & 410 \\
& Asap motor & 360 & 475 \\
& Asap Obat nyamuk & 460 & 496 \\
\hline
\end{tabular}

*Sumber : Hasil pengukuran

\section{SIMPULAN}

Dari hasil analisa dan pengujian yang dilakukan maka dapat diambil kesimpulan bahwa:

1. Ketika indoor atau berada pada satu ruangan, alat dapat berfungsi secara maksimal karena dapat mendeteksi gas yang ada didalamnya dengan akurat.

2. Ketika outdoor atau pada luar ruangan, alat masih dapat mendeteksi gas apabila gas yang ada disekitarnya telah menyelimuti tebal dengan jarak deteksi maksimal kurang dari $1 \mathrm{~m}$.

3. Pengontrolan alat ini menggunakan Mikrokontroler dan jaringan GSM dengan aplikasi SMS dalam pengoperasiannya. 
4. Alat ini dapat menampilkan kadar gas CO dan NO2 secara real time sesuai dengan kadar gas yang dideteksi dan dapat mengkoneksikan Mikrokontroler dan aplikasi SMS secara bersamaan.

\section{DAFTAR PUSTAKA}

[1]. Cristo tjahjadi, Karakteristik dan Dampak SO2, CO2, dan NO2 [online], diakses pada 29 Juli 2016, Available: http://airveronmental.blogspot.co.id.

[2]. Gerai cerdas, sensor MQ-7[online], diakses pada 29 Juli 2016, Available: http://www.geraicerdas.com.

[3]. Gerai cerdas, sensor MQ-5[online], diakses pada 29 Juli 2016, Available: http://www.geraicerdas.com.

[4]. Saryan Khan, Spesifikasi ATMega16 [Online], diakses pada 20 Juni 2016, Available: http://pintaberilmu-saryan.blogspot.com/2012/10/spesifikasi-atmega16.html.

[5]. Golek Sangu, Sistem minimum ATmega16 [Online], diakses pada 20 Juni 2016, Available: https://kurangsangu.wordpress.com/2011/04/19/sistem-minimum-atmega16/.

[6]. John Myers, Liquid Crystal Display in Industrial Systems, Bandung, 2002.

[7]. Matrik keypad 4x4, keypad[online], diakses pada 29 Juli 2016, Available : http://elektronikadasar.web.id

[8]. Festo, Relay[Online], diakses pada 24 Juni 2016, Available : http://www.festodidactic.com.

[9]. Agam Zulpadli Pratama, Modem GSM wavecom[online], diakses pada 29 Juli 2016, Available : http://fungsimodemwavecom.blogspot.co.id/

[10]. Skema Rangkaian PCB, skematik power supply [online], diakses pada 15 Agustus 2016, Available : http://skemarangkaianpcb.com 